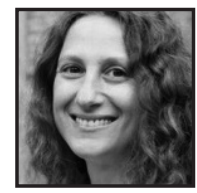

\title{
Feels Like Home: Writing Alone Together at School
}

\author{
Ahava Shira
}

\begin{abstract}
Writing Alone Together ${ }^{1}$ builds community in meaningful ways through creative engagement in four practices: Writing Freely, Reading Aloud, Listening Deeply, and Bearing Witness. This article shares how I have been using this innovative process to foster play, multi-literacies, and mental health in a group of intergenerational writers $^{2}$ at the Gulf Islands Secondary School on Salt Spring Island, British Columbia.
\end{abstract}

\section{Words at Play}

Maybe writing, by acting as a site of self-construction, is one of the dominant ways people in the modern world create a sense of who they are, and how they relate to others. Maybe it is time to reconsider the value of writing and what it means to write. (Park, 2005, p. 3)

A person arrives at a sense of authenticity in life through the performance of his or her stories to an appreciative audience, with a sense of that the play fits what is expected. (Mehl-Madrona, 2005, p. 155)

was 20 years old when I wrote my first journal and started to experience writing as a liberating practice in which I could say what I wanted and explore what really mattered to me, without worrying whether anyone would judge me or my expression. After many years of writing alone, I connected with two women who were also long-time journal writers. 
We knew many of the same books and authors, discovered familiarity and commonalities in our experiences with journal writing and to the ways it had sustained us in our lives. Coming together in a journal writing circle with Ahava and Lynda felt natural to me, a kind of coming home-to ourselves, to the comfort of our written words and sharing with one another.

(Cutler, Monk, \& Shira, 2014, p. 28) (Italics mine)

Over the next eight years, the three of us slowly developed the four practices of Writing Alone Together. Through a journey of creative inquiry, we discovered how to bring what is typically regarded as personal and private experience, into community.

\section{Seeking Lines of Connection}

Writing is not simply self-expression. Writing is a way to seek lines of connection and intersection with others, to compose creative and lively possibilities for living stories, for making up stories, for revising stories, for turning stories inside out and upside down so they are always transforming and transformative.

(Hasebe-Ludt, Chambers, \& Leggo, 2009, p. 154)

Although many writing programs exist to help youth write and reflect on the narratives of their lives, most focus on the support of one-to-one adult mentorship. Writing Alone Together is a practice of gathering with others to create a sense of community through journal writing.

In the fall of 2011, I was invited to mentor young writers in the local high school. Organized by Connecting Generations ${ }^{3}$ (CG), the GISS ${ }^{4}$ writers' group started to meet after school, funded through a collaboration between the Salt Spring Arts Council's Artist in the Class program and the Gulf Islands school district. Here was an opportunity to test out the four practices of Writing Alone Together with a group of youth and adults.

As the group met and wrote together that first semester, not only were the youth learning to tell and share their stories, but they were also discovering Writing Alone Together as both "a catalyst for creative self-expression and mutual support" (Cutler et al., 2014, p. 2). The GISS writers' group provided a safe, caring, non-judgmental space where the youth and adults could experiment with language, meaning, story, and image. As they were seen, heard, and witnessed by peers and caring adults 
in the community, the writers experienced a deep sense of interconnectedness and reciprocity.

As they described in a collaborative group poem:

The Writers' Group is like a little family.

One which bonds through shared words.

Shared snacks, shared time, space and fun.

A place where food feeds our bellies and words feed our souls.

A place to be inspired. A place to create.

Writers' Group feels like home.

\section{Engaging the Four Practices}

When we come together-to write, to read, to listen, to witness - we are living our creativity. (Cutler et al., 2014, p. 5)

The fragment might lead to clusters, to molecular structures, collaborations, artifacts, and institutions which retain the curiosity and flexibility of youth without sacrificing the digested experience of maturity, so that generations and genders no longer see themselves as competitive with each other. (Lauterbach, 2005, p. 11)

Over the past five years, the writers' group has grown from a small circle of six eager girls led by one passionate mentor, to a group of multi-gendered and multigenerational students (from grades 9-12) and adults (ages 20-66) facilitated by two creatively diverse mentors. Owing to writers sharing their enthusiasm with peers and others in the community, the group has gained a reputation as a place where students can flourish literately and socially. Adults have been drawn in by the opportunity to foster meaningful relationships with youth that are not their offspring.

Functioning as a dynamic artistic community that values each person's unique perspectives, week after week, the writers develop their voices on many topics: home, nature, family, cultural legacies, relationships, memories, dreams, joys, fears and other human preoccupations. The mixed generations of students and adults support the writers to reach past their personal experience and discover how the world looks and feels to someone of another age and perspective. 
Through engaging in the four practices of Writing Freely, Reading Aloud, Listening Deeply, and Bearing Witness, the writers co-create a safe, playful, non-judgmental space in which they can relax and open to their creativity. Returning to this simple structure, again and again, the writers explore their passions, make meaning of their experiences, and grapple with the daily challenges of their lives.

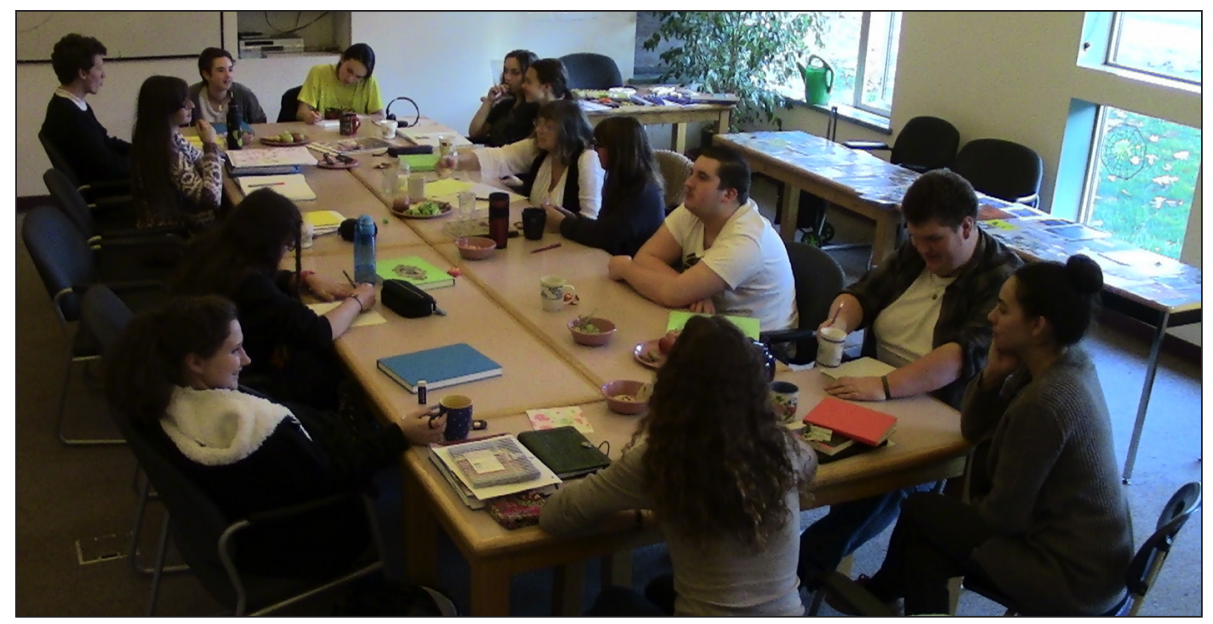

Fig. 1: A safe, playful, and non-judgmental space

\section{Writing Freely}

Writing freely is to follow one's own impulses and put down whatever comes. We start with a word, phrase, memory, image, question, quote, feeling or body sensation. There are hundreds of ways to come to the page. (Cutler et al., 2014, p. 39)

To inspire the writers' creativity, we begin every session with a timed writing of 10 to 15 minutes. This invites the writers to dive in and trust the improvisational free fall of their words. In order to facilitate this trust, we encourage the writers to practice curiosity and openness with whatever they are writing. As they practice this free writing, they learn to be comfortable with the unknown, to embrace playfulness and spontaneity, and to welcome the power and possibilities within their own imaginations. Engaging in this spontaneous creative expression within the limits of a specific amount of time, each writer finds their particular path to expression.

Making the commitment to show up at a regularly scheduled meeting is also important. As one writer shares: "Time and space to write, time in your week to put aside other things and just write and listen, it's hard to always find time as we are busy, it's a commitment." 


\section{Writing Prompts}

I always begin each session by offering a prompt to the writers. Sometimes this is in the form of a quote, poem, story, or "word of the day," or a newspaper article I read before coming to the group. More often, I rely on the stimulus I get from listening to what arises as we sit around the tables, eating snacks and settling in. Prompts have been inspired by comments one of the writers has made during an informal check-in or a piece of music playing on another writer's iPad.

Sometimes the prompts are content-based:

- Write about an experience that transformed your sense of identity.

- Describe an activity you engage in regularly as if you are doing it for the first time.

Sometimes they are form-related:

- Write a poem with only three words to a line.

- Create a found poem out of the words of another poem.

Topics the writers have explored include: what keeps me sane, what's in my head, how we practice generosity, our inner warrior, something that happened that changed the way we saw the world, what we are most proud of, what's our poison, and what's the antidote.

The prompts may give the writers a "way in," however, each writer interprets them uniquely, taking their writing in its own direction. As one writer acknowledges: "The prompts help with inspiration, direction, even if you don't use them, like you might end up writing the opposite."

Another writer offers: "Sometimes I have a hard time writing and the prompt widens my range when I write."

\section{Reading Aloud}

When we read aloud, we connect with the feelings and emotions of our words, which may not be apparent when we are writing them down or reading them silently to ourselves. It is natural to feel vulnerable, hesitant, frightened and uncertain when reading our words aloud. We may also feel excited, enthusiastic and eager. (Cutler et al., 2014, p. 44) 
After writing, I invite the writers to share their freshly written words with the group. This is always voluntary. I understand, because of the improvisational nature of the process, there may be things the writers have written which they do not want to share with others.

There is a feeling of genuine interest and curiosity that builds as we move around the group, each writer taking us with them, sharing their unique, wide-seeing, and wise-sensing expressions. It builds courage, confidence, and emotional intelligence. A practice of both giving and receiving, Reading Aloud stretches the writers verbally, emotionally, and socially. As one writer recognizes: "You're making yourself vulnerable, everyone is giving a part of themselves up."

I have come to consider another way to look at Reading Aloud. If spelled "allowed," the experience becomes one of having permission to speak, to share, and to give voice. Youth often express disappointment at feeling unseen, unheard, and unknown by adults in their lives. Some youth feel stereotyped and dismissed when they encounter adults in their community. Likewise, some adults feel uncomfortable connecting with youth.

At the writers' group, both the youth and adults have a space to speak their thoughts and emotions, tell their stories, poems and memories, and air their worries and stresses, in an atmosphere of acceptance and care. Providing this space feels nourishing and uplifting.

Feeling appreciated for whatever they write, the writers learn to trust themselves and their writing process. They also experience the joy and pleasure of reading to, and being read to, by one of their peers. 


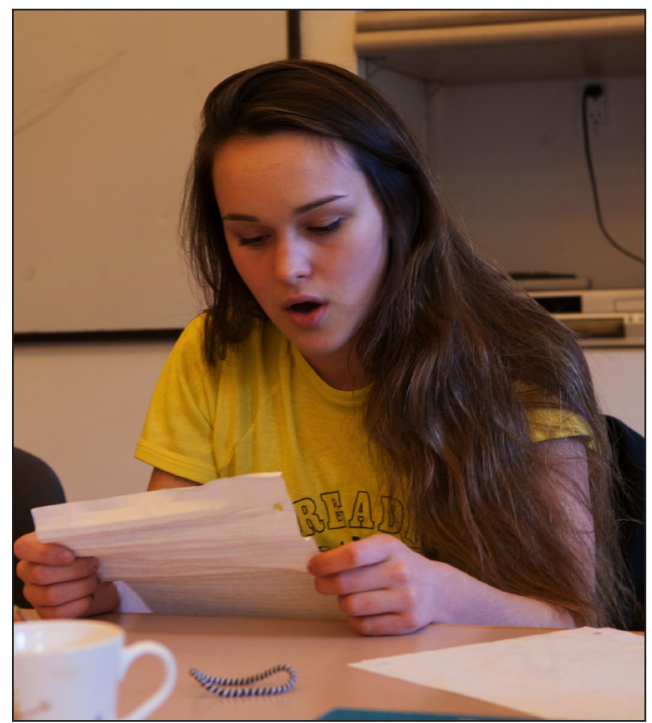

Fig. 2: The pleasure of reading

\section{Listening Deeply}

After a writer has read, we share our feelings, impressions and, most importantly, our supportive comments... A format that prioritizes sharing without critique enables us to suspend judgment and internal doubts and to be authentic with our writing, our thoughts, our words and one another. (Cutler et al., 2014, pp. 48-49)

As the facilitator, I encourage the writers to listen with openness, curiosity, and wonder to each writer's words, rather than judging them as "bad" or "good," "right" or "wrong." This shifts our focus from analyzing, interpreting, or improving each other's words, to acknowledging the value and inherent worth of the writing. Through listening to each other's unique voice and expression, the writers learn to pay attention beyond their habitual ideas and opinions, and in doing so, they learn to create a space of belonging for everyone.

Exposed to a wide range of writing in response to each prompt, they learn there are as many ways of seeing, telling, and being as there are writers. They also learn to give each other attention and to receive attention, a kind of attention that honours and supports. This giving attention is vital to the process. As one writer affirms: "You are not just waiting for your turn, you are listening and appreciating that everyone is putting themselves out there." 
Although the writers do not critique each other's words, there is plenty of opportunity to support each other with positive comments. After each writer has shared, we acknowledge them by offering a reflection of what we have heard. We may share how particular words, phrases, or ideas inspired us, how a certain metaphor or voice surprised us, or how the flow or rhythm in the piece moved us.

As the writers receive these reflective comments, they learn to value their unique strengths and those of the other writers. Over time, they become more comfortable with sharing their writing, taking risks and trying on new voices, stories, and genres. One of the writers expressed: "Receiving valuable artistic feedback on your work, then you get to make it better."

\section{Bearing Witness}

It is a way of interacting with respect for another human being that honours who they are and what they are sharing. It is a skill and a decision to show up for one another with commitment and engagement. (Cutler et al., 2014, p. 50)

When the writers share their writing with each other, they are agreeing to be vulnerable, and to show aspects of themselves that are often private, hidden parts. As they read their writing, they are saying, "I am prepared to be seen by you, to be witnessed. I trust that you will hold this with respect and care" (p. 50).

To create a safe, respectful, and trusting emotional space for this type of sharing, we remain in silence while someone is sharing. Then, when one of us has finished reading, the rest of the group raises their hands and waves their fingers in the air. Through this visual appreciation-often used by sign language learners in place of clapping-the writers receive an immediate affirmation for their creativity and courage.

Through this witnessing, the writers learn to relax and trust they can share their deepest truths, and wildest imaginations, and that they will be heard. They also learn to practice empathy and compassion as they witness the emotional honesty and vulnerability of each writer.

One writer acknowledges: "There aren't many other places where we learn as much about each other." 
Holding the space for all of who we are, we experience the power of what Prendergast, Leggo, and Sameshima (2009) name "a calling between the 'I' and the 'Other', a call-and-response" (p. xxxv). Hasebe-Ludt and colleagues (2009) expand: "We learn to practice this generosity of spirit in relation to ourselves and others, acknowledging how we are all inextricably and ecologically connected, all of us needing to be heard" (p. 154).

\section{Developing Multi-Literacies}

I want to talk about images. The images that come to us and tell us things. Sometimes they come from inside, and sometimes they come from outside. One needs to pay attention when they come. (Holzer, 1994, p. 68)

The fragments among which we live are, in my opinion, cause for celebration rather than lament, an invitation to create new ideas of coherence, where boundaries are malleable and permeable, so that inclusion and exclusion are in unstable flux. The fragment offers a possibility of vitality and variety-multiple perspectives, disparate vocabularies. (Lauterbach, 2005, p. 11)

During the second year of our group, one of the adult writers brought her passion for collage-making to the group. Since then, we have been using both writing and multi-media collage as tools for Writing Alone Together. Students have access to a diversity of materials - including text and images, markers, pastels, watercolor pencils, acrylic paints-which they can use to create art in response to the "prompt" which the collage artist offers each week.

Combining our writing with this exploration through images adds another vital layer to the creative process of the writers' group. The metaphors of our words can be heightened and expanded in our collages. The scratching of pens on the page becomes the staccato shuffling of papers and the soft brushing of markers, crayons, and pastels. Our inward focus finds another form, many. We move through the rhythms of creation, again and again. 


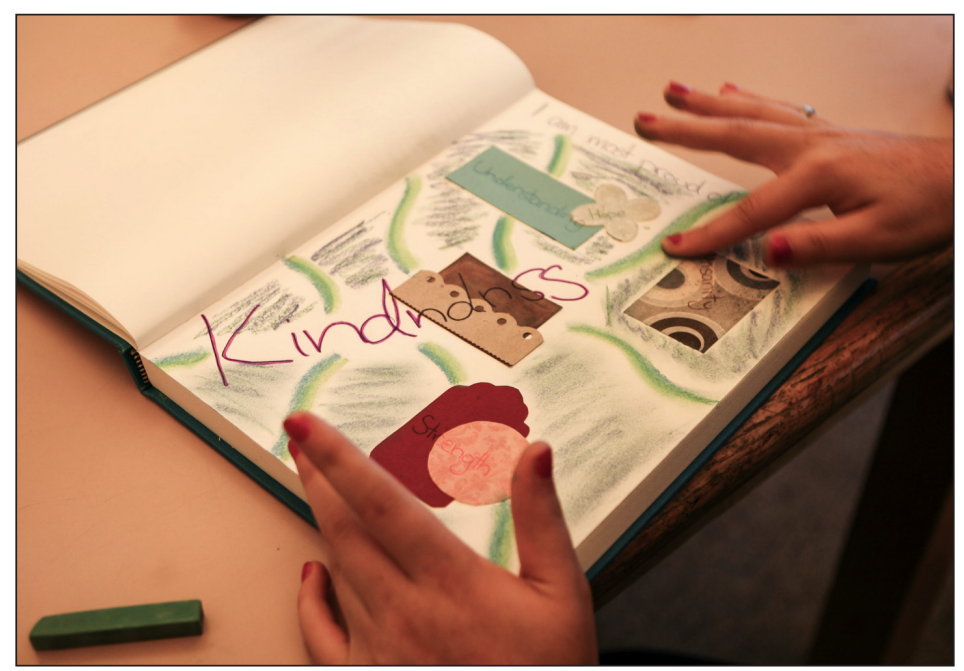

Fig. 3: A writer's collage

On one particular Thursday, one of the writers suggested we tell a story orally as a group. As we spoke around the circle, each of us added our piece to the story:

\section{Writers of the Square Table}

Once upon a time, although it wasn't really all that long ago, there was a fantastic circle of wise writers who gathered every week in the same place at the same time in a strange wooden-ceilinged room.

They were the Writers of the Square Table. Instead of weapons, they wielded their pens of glory. Together they held their writing tools high as they fought against the white pages of writer's block.

Along their gallant way they made quite a name for themselves in the small town where they lived.

They wrestled alongside each other, bravely using each other's weaknesses as their advantage. They wrote with their eyes, sowed words and ideas, images and stories with everything they knew.

For each warrior knew that every warriors' weakness was their own. 
When they used their writing and collaging instruments, they gained power to share their worlds with each other. They shared what they thought through words and pictures.

Side by side they uncovered vulnerabilities and sad days but they got through it.

After we told the story, we reflected on how we made it happen. We realized how we created the story is how we do everything in our group. We make it up out of our imaginations. We dare to go we "know not where," until our pens, journals, images, and paintbrushes take us there.

When asked to share some words to describe how this spontaneity happens, the writers offered: We "create, connect, turn weakness into strength, unknowing into possibility, risk, show up, care, try, eat, laugh, hold the silence, feel the thoughts, and experiment. It's a part of the space we create."

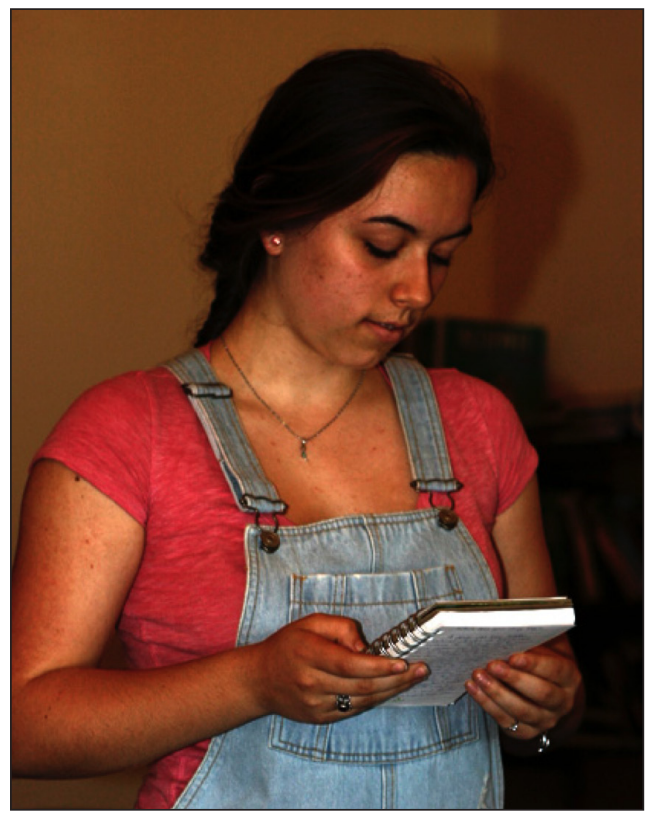

Fig. 4: Spontaneity at work 


\section{Promoting Mental Health and Resilience}

Bringing our bodies, words and stories together in the same room is significant. Coming together as equals with mutual respect is radical. Over time, Writing Alone Together creates a structure that transforms who we are individually and collectively. (Cutler et al., 2014, pp. 5-6)

Youth mental health is a growing concern in schools and communities across Canada and around the world (Thomson, 2014; Tilleczek \& Campbell, 2013; Kutcher \& McLuckie, 2010). On Salt Spring Island, according to the results from a 2012 Community Needs Survey, ${ }^{5}$ Mental Health emerged as the second most critical issue. In his studies on Learning and The Adolescent Brain, Dr. Stan Kutcher (2012), Professor of Psychiatry at Dalhousie University, recognized youth for their flexible attitudes, natural innovation, and ability to see things in different ways. He also acknowledged their propensity toward inaccurate readings of emotional states of others. In considering what schools could do to support adolescent mental health, Dr. Kutcher asked:

- How can schools be structured to enhance development of capacities for "emotional intelligence"?

- What kind of school-based activities or curricula could be used to improve adolescents' abilities to experience, identify, process, understand, and evaluate emotional clues (in themselves and others)?

As an example of the kind of school-based activity Kutcher calls for, Writing Alone Together improves adolescents' abilities to "experience, identify, process, understand, and evaluate emotional clues." Writing with others from a range of generations cultivates a community of encouragement and support and diminishes their social isolation, depression, and anxiety. It is an accessible, democratic, pluralistic approach where nothing is rejected. In these few hours of writing, sharing and caring for each other, the writers learn to practice self-awareness while being attentive to others; to know their own wholeness while belonging to a greater whole; to dwell in wonder, play, and mystery and to be uniquely and flexibly themselves, changing and growing through time.

Having experienced supportive and constructive connections with other youth and adults, the writers develop resilience, becoming the kind of human beings whose voices and visions contribute to making the world a better place to live. Writing Alone Together is transforming the possibilities for being and belonging at school and in the community.

Try it yourself. You will see, it will feel like home. (Cutler et al., 2014, p. 10) 


\section{Notes}

1. Writing Alone Together: Journalling in a Circle of Women for Creativity, Compassion and Connection. Wendy Judith Cutler, Lynda Monk, and Ahava Shira.

2. Originally conceived for women writing in a circle, Ahava has adapted these practices to be supportive of diverse writers' needs.

3. A program which supports people of different ages and backgrounds in the Gulf Islands to have meaningful conversations about things that matter to them. See www.connectinggenerations.net.

4. Gulf Islands Secondary School.

5. Salt Spring Foundation.

\section{References}

Cutler, W. J., Monk, L., \& Shira, A. (2014). Writing alone together: Journalling in a circle of women for creativity, compassion and connection. Salt Spring Island, British Columbia: Butterfly Press.

Hasebe-Ludt, E., Chambers, C. M., \& Leggo, C. (2009). Life writing and literary métissage as an ethos for our times. New York: Peter Lang.

Holzer, B. N. (1994). A walk between heaven and earth: A personal journal on writing and the creative process. New York: Bell Tower.

Kutcher, S. (2012). The adolescent brain: Implication for educators and school. Summer Institute, School Mental Health: Vancouver, British Columbia. Retrieved from http:// www.cw.bc.ca/OnlineCourses/mediasite/ FORCE/TeenMentalHealth_SlideDeck.pdf

Kutcher, S., \& McLuckie, A. (2010). Evergreen: A child and youth mental health framework for Canada. The Child and Youth Advisory Committee, Mental Health Commission of Canada (Calgary).
Lauterbach, A. (2005). The night sky: Writings on the poetics of experience. New York: Penguin Books.

Mehl-Madrona, L. (2005). Coyote wisdom: The power of story in healing. Rochester, VT: Bear and Company.

Park, J. (2005). Writing at the edge: Narrative and writing process theory. New York: Peter Lang.

Prendergast, M., Leggo, C., \& Sameshima, P. (Eds.). (2009). Poetic inquiry: Vibrant voices in the social sciences. Rotterdam, The Netherlands: Sense Publishers.

Thomson, H. (2014). Writes of passage. Trek Magazine, Spring. Retrieved from http:// trekmagazine.alumni.ubc.ca/2014/ may-2014/features/writes-of-passage/

Tilleczek, K., \& Campbell, V. (2013). "Barriers to youth literacy: Sociological and Canadian insights," Language and Literacy, 15(2), 77-100. 


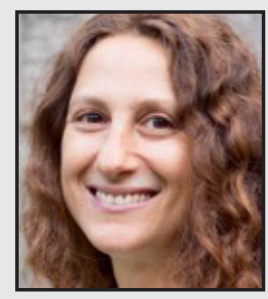

Ahava Shira is a writer, expressive arts educator, and creative mentor of the GISS writers' group, with whom she has co-edited three anthologies of intergenerational writing: Scattered Change, Paper Airplanes, and Writers of the Square Table. Author of a book of poetry and a spoken-word CD, her poems and articles have been published in several journals and books including The Art of Poetic Inquiry, Living Artfully: Reflections from the Far West Coast, and A Heart of Wisdom: Life Writing as Empathetic Inquiry. Through Loving Inquiry, she mentors a vibrant community of artistic women. 